\title{
Familias póstumas. Literatura argentina, fuego, peronismo. Manuel Mujica Lainez, Beatriz Guido, David Viñas. 1953-1963.
}

Zangrandi, Marcos (2016)

Buenos Aires: Godot, 284 pp.

\section{(1) Nicolás Suárez UBA-UNA-CONICET}

Uno de los primeros datos que saltan a la vista a partir de la lectura de Familias póstumas. Literatura argentina, fuego, peronismo. Manuel Mujica Lainez, Beatriz Guido, David Viñas. 1953-1963, de Marcos Zangrandi, es la habilidad con que el autor se mueve, a menudo de manera casi imperceptible, en un campo transdisciplinario que hace de este libro un material de lectura atractivo tanto para el público interesado en los estudios literarios como en los estudios sobre cine, la historia cultural y los estudios de género. El trabajo, surgido de una tesis doctoral, se propone explorar diferentes modalidades de una interrupción del orden familiar patriarcal que se puede rastrear en buena parte de la narrativa argentina de los años cincuenta, y su relación con las transformaciones políticas, sociales y culturales abiertas por el fenómeno del peronismo.

El texto se organiza en cuatro capítulos, precedidos por una introducción donde se presenta el concepto de 'familias póstumas', que da título al libro. La idea principal de la obra, así, sería que la repetición de diversas imágenes de familias póstumas (entendidas como aquellas que se constituyen luego de la caída del padre) es el procedimiento mediante el cual un conjunto de narraciones de Beatriz Guido, David Viñas y Manuel Mujica Lainez procesan, en el período que va de 1953 a 1963, los cambios producidos en la organización familiar por una serie de políticas desarrolladas durante la década peronista (principalmente, la ley de divorcio y el reconocimiento de los hijos "ilegítimos"). Para el peronismo, el impacto simbólico de estas transformaciones apuntaba a crear un ideal familiar de integración de los sectores marginados. Pero las familias póstumas de Zangrandi constituyen no solo un enclave donde se cruzan diversos cortes culturales, sociales, ideológicos y generacionales, sino también un procedimiento central para la construcción de distintas ficciones, bajo la forma del desmoronamiento de una serie de preceptos domésticos, filiales, sexuales y de legitimidad. En la introducción, asimismo, se fundamenta la periodización. A diferencia de algunos textos canónicos referidos al período, como Nuestros años sesenta (1991), de Oscar Terán, e Intelectuales y poder en la década del sesenta (1991), de Silvia Sigal, que periodizan la década del cincuenta según un criterio político-institucional que va de un golpe a otro (19551966), Zangrandi incorpora un criterio doble, político y cultural. Dicho criterio toma, como punto de inicio, la jornada de incendios y explosiones del 15 de abril de 1953, luego de la cual el enfrentamiento entre el gobierno y la oposición se acentúa fuertemente y se empieza a visibilizar, en el campo de la cultura, una tendencia hacia el compromiso político de la figura del intelectual. En cuanto al armado del corpus, el corte de inicio está justificado por la publicación en 1953 de Los ídolos, de Mujica Lainez, el primer acercamiento de Guido al cine a través de su colaboración en el guion de Días de odio y la aparición del primer número de Contorno y de tres novelas policiales que Viñas publicó bajo seudónimo.

El capítulo uno, titulado "El incendio en la literatura", termina de completar el criterio de la periodización. Adoptando una perspectiva originalísima y poco habitual en los estudios literarios en la Argentina, un punto de vista, podría decirse, propio del campo de la cultura material, Zangrandi repasa el incendio del Jockey Club en 1953 -que Guido retoma en su novela El incendio y las vísperas - y encuentra, en el fuego, una fuerza política que atraviesa gran parte de los textos del corpus y es capaz de sacudir los cimientos del edificio cultural de la patria en cuanto 
construcción blindada respecto del conflicto social y político, según había querido el proyecto diseñado por las elites liberales de fines del siglo XIX. El incendio y las vísperas es de 1964; a fines de 1962, Viñas renunciaba a la narrativa para comprometerse de Ileno con la lucha política. El año 1963, pues, como punto medio entre estos dos acontecimientos, viene a señalar que - una década después del inicio del ciclo de las familias póstumas- las condiciones del campo intelectual estaban cambiando hacia un proceso de politización y antiintelecualización que marca el cierre del ciclo (visible, en el caso de Mujica Lainez, por su abandono de la saga porteña en favor de una serie de búsquedas histórico-míticas). Luego de trazar esta visión panorámica de la vida sociocultural de la época y del marco incendiario en el que circulan las narraciones, este capítulo se dedica a recorrer las trayectorias, posicionamientos y cruces de los tres autores, poniendo el foco en los diferentes modos en que la cultura y la política quedaban vinculadas en la época. A este respecto, Zangrandi destaca la dimensión performática de la figura de Mujica Lainez (cuya pose de dandi lo sitúa en una posición ambivalente entre el imaginario aristocrático y el antipuritanismo), la condición de médium de Guido (como agente modernizador de la cultura entre América y Europa, la literatura y el cine, e incluso entre los muertos y los vivos) y la imagen de Viñas que - $n$ función del hallazgo de sus novelas policiales realizadas por encargo- se presenta como un "escritor bilocado" (69) (antiperonista, liberal de izquierda, sofisticado y parricida, de un lado, y masivo y popular, del otro).

Los siguientes tres capítulos abordan diferentes rupturas de la institución familiar y sus vínculos con la dinámica política y cultural: las discontinuidades entre padres e hijos, la fractura del eje público / privado y el derrumbe del espacio doméstico como garantía de la legitimidad territorial. El segundo capítulo trabaja sobre dos figuras fundamentales. Por un lado, la del parricidio como retórica mediante la cual la literatura argentina se configuró a sí misma frente al desafío político y cultural del peronismo. De este modo, el debate público sobre el problema de la legitimidad filial -instalado por una ley de 1954 que, entre otros objetivos, buscaba legitimar la condición de hijos "naturales" de Perón y Eva- se introduce en la narrativa argentina, según Zangrandi, a través de tres modalidades: el declive paterno (en Cayó sobre su rostro [1955], de Viñas, y La casa [1954], de Mujica Lainez), la construcción de un mundo yermo y melancólico luego del corte del linaje (por ejemplo, en La casa del ángel [1955], de Guido) y la emergencia de los hijos como restauradores paternos (en los policiales que escribe Viñas con el seudónimo de Pedro
Pago). Por otro lado, el hallazgo de una fotografía de la destrucción de un monumento a Eva en un álbum de recortes comentados por Mujica Lainez le sirve a Zangrandi para postular la figura del gigante demolido en cuanto alusión simbólica al peronismo como coloso derribado, que a su vez se articula en relatos como Fin de fiesta (1958) y Cayó sobre su rostro con la pérdida de figuras tutelares y la experiencia de los hijos que deben vivir entre los escombros de la autoridad paterna.

El tercer capítulo es el más extenso del libro y resulta fundamental para su argumentación. Aquí se examinan las formas en que la literatura recurre a un enrarecimiento de la separación burguesa entre lo público y lo privado, cuyas causas se encuentran tanto en las transformaciones de un afuera peligroso como en las incapacidades internas del propio hogar para afrontar esos cambios. Adolescentes perversos, prostitutas, sexualidades disidentes, criados que devienen obreros asalariados (y, por lo tanto, sujetos deseantes) son algunas de las figuras que emergen de este malestar familiar. Zangrandi las releva, analiza y contrasta valiéndose de un sólido aparato teórico y un amplio conocimiento del campo de los estudios de género en la Argentina. Finalmente, el capítulo se cierra con un anexo sobre Los ídolos (1953), de Mujica Lainez, y su recepción en diversas publicaciones. Este abordaje le permite a Zangrandi establecer una singular lectura de los argumentos homofóbicos que expone Héctor Murena en su ensayo "La erótica del espejo" (1959) como una respuesta tardía a la novela de Mujica Lainez.

Por último, en el cuarto capítulo, la casa como figura desestabilizada o destruida por conmociones internas y externas se abre al problema de la legitimidad de la propiedad de la tierra. Tomando distancia respecto de algunos ejemplos recurrentes en la lectura del peronismo (como "Casa tomada" [1947], de Julio Cortázar, y Cabecita negra [1961], de Germán Rozenmacher), las narraciones que estudia Zangrandi no se inscriben en la línea de la invasión sino en la de los umbrales y "el efecto traumático de un exterior alterado sobre el interior anquilosado" (212). En este sentido, el autor se detiene en la asociación destructora de capitalismo industrial y peronismo en La casa y Los viajeros (1955), de Mujica Lainez, el imaginario de la casa como borde asfixiante para sus propios moradores en las narraciones de Guido, y la idea de la casa como límite burgués frente a las clases populares en el guion de El jefe (Fernando Ayala, 1958) y en Los años despiadados (1956), que Zangrandi sagazmente a su vez relaciona con la equiparación de la casa y el cuerpo violado que Viñas más tarde plantearía en 
De Sarmiento a Cortázar (1971). Adicionalmente, este capítulo indaga la actualización de la tradición gótica anglosajona para crear un clima de duelo familiar en torno a la casa como objeto de destrucción, sobre todo en los relatos de Guido.

Entre los varios logros de Familias póstumas..., la singularidad del enfoque teórico es sin duda un primer punto para subrayar. Dentro de un ámbito tan frecuentado como el de los estudios sobre el peronismo, Zangrandi encuentra una perspectiva propia. Ello se debe, en buena medida, a la decisión metodológica de abordar las configuraciones familiares en relación con el peronismo con una fuerte base en la teoría de Élisabeth Roudinesco y desde el lugar bourdiano de la "dominación masculina", menos transitado que el de las figuras maternales y caritativas tan cercanas a Eva.

En segundo lugar, el trabajo de archivo es otro de los logros más resonantes de Familias póstumas... Ese trabajo se advierte, de manera palmaria, en varios de los "descubrimientos" que guarda el libro: las novelas policiales que Viñas publicó en la editorial Vorágine (compiladas por el propio Zangrandi en un volumen editado por la Biblioteca Nacional en 2012); algunos relatos prácticamente desconocidos, como "Paredes huecas", de Guido, y "Un poco de bondad", de Viñas; el examen del archivo y la biblioteca personal de Mujica Lainez; y un exhaustivo relevo de las diferencias entre las versiones originales de algunas narraciones de Viñas y Guido, y los guiones cinematográficos basados en esas obras, que ellos mismos elaboraron. La minuciosidad de la investigación de Zangrandi, además, se manifiesta en la profusión de notas al pie, mediante las que el autor generosamente señala caminos alternativos, dispara relaciones inesperadas y anticipa, acaso, investigaciones futuras.

Por último, de modo más general, merece destacarse la originalidad en el armado del corpus. Hasta ahora, los nombres de Guido, Mujica Lainez y Viñas no habían sido reunidos en un único estudio. Viñas con Guido era una articulación relativamente previsible, sobre todo en virtud del rol que ambos desempeñaron como modernizadores del cine y la cultura en la etapa posperonista. Guido con Mujica era otro par más o menos esperable, en función, por caso, de la extracción de ambos autores y del modo en que los dos retrataron la vida de las clases altas argentinas. Viñas y Mujica Lainez, incluso, aunque sea por contraste entre dos posiciones claramente diferenciadas en el arco ideológico, era otra combinación imaginable antes de la publicación de Familias póstumas... Pero el estudio simultáneo de la obra de estos tres escritores es aquí lo novedoso. En esa constelación, el lugar de Guido resulta crucial no solo porque como ha señalado Nora Domínguez en una aguda reseña publicada en Review. Revista de libros- el libro se abre y se cierra con ella, sino también por el lugar que adopta como tertium comparationis entre Mujica Lainez y Viñas. En este otro sentido, Guido también sería, para emplear el término que usa Zangrandi, una médium. Acaso uno de los mayores méritos de su libro justamente sea que, luego de leerlo, ese contacto que en principio podría haber sido apenas una posibilidad de lectura, se nos figure como necesario. Es que, después de Familias póstumas..., no se puede seguir leyendo de la misma manera a Mujica Lainez, a Viñas y a Guido. Ya no se puede, en efecto, sino leerlos juntos. 
